Four groups of sites within a two-mile radius of the Mountain Cow Water. Hole area were excavated. Of these, two, Hatzcap Ceel and Cahal Pichik, were ceremonial centres and two, Tzimin Kax and Cahal Cunil, were residential sites.

The two ceremonial centres flourished at the close of Cycle 9 and the beginning of Cycle 10 in Maya dating. Evidence for this is afforded by two dated monuments, of which the dates correspond to A.D. 835 and A.D. 910. There is evidence also of a succession of construction periods in the superposition of buildings, though not all these must be taken to represent distinct culture phases. The pyramids were found to be in a collapsed condition. Each of the ceremonial sites possibly had a ball court between two pyramids. Most of the pyramids of the temple type yielded votive caches. The contents of these caches were generally uniform in character, seven of the ten found containing characteristic small figurines of jade, slate, or shell. Other offerings were jade and small objects, including a worked flint of eccentric form with three arms, or points, two lobster-claw-shaped and one tau-shaped, In five of the seven caches containing figurines were containers in the form of a barrel-shaped cylindrical urn. One of the offerings is a mask which is undoubtedly the finest jade object yet found in British Honduras. It is now in the British Museum. A mirror of iron pyrites was found at Hatzcap Ceel, but the remains of what was probably a second were too far corroded to permit of certain identification.

The evidence of the pottery showed that these two sites belong to the same general cultural area as Holmul, Yalloch, and Uaxactun-an area in which art, as exemplified in stone carving on altar and stelæ, did not fall far short of that of the larger cities of the Peten region in what is now Guatemala; but architecture and the ability to erect large carved stone monuments did not penetrate here until late in the Old Empire period. It would appear that the art of erecting large multiple vaulted buildings never reached the Mountain Cow Water Hole region.

The two residential sites, Tzimin Kax and Cahal Cunil, consist of a number of scattered plazas of small size, constructed on the tops of natural hillocks enlarged by piling around them masses of stone and rubble up to a height of three or four feet above the natural summit. The whole was then levelled up, and pyramidal square and low oblong mounds erected at the edge of the platform thus constructed. The platforms average twenty-five metres in each direction and are orientated within three or four degrees of true north. The outside walls were made of blocks of stone roughly faced but unsquared. The fill is of large limestone boulders and a small amount of rubble, but is loose. There is evidence that the platforms were reconstructed on several occasions.

A number of burials was associated with most of the plazuelas. This would be fully in accord with what we know of Maya practice. Bishop Landa says that it was customary for the people of Yucatan to bury their dead under the house, and among the modern Maya, children are buried under the floors of the huts. It is to be noted that in a burial at Tzimin Kax a number of small crude pots were found in pairs, one being placed mouth downwards over the other. Three of these contained bones: in one the first, second, and third dactyls of a human hand, judging by its size, of a woman or adolescent; and in a second a single bone, which proved to be the second dactyl of a small adult's hand. Dr. Gann also records the finding of the terminal phalanx of "a Maya lady's little finger" from a burial near Progreso. The skeletal remains were in a bad state of preservation, but Prof. Elliot Smith reported on two skulls as showing marked antero-posterior deformation.

The two residential sites were evidently occupied for a longer period than the ceremonial centres. Reference to the classification made by Dr. Vaillant at Holmul shows that all four sites were occupied in the period Holmul V., while the earlier period of Holmul I. is represented in burials at both the residential sites. At Cahal Cunil there is certain evidence which points to a still earlier period of 'pre-Holmul'. Pottery of the same type has been found at Uaxactun in conditions which point to its being earlier than Holmul I. It must be remembered that although this correspondence with Holmul is established in the Mountain Cow Water Hole area, it does not necessarily follow that in absolute dating the two are contemporary; the latter being a peripheral area, Holmul pottery may have reached it at a later date. It is clear that the sites were not occupied after the introduction of metal.

\title{
Forecasts of Fisheries
}

AEPORT of the activities of the various area committees of the International Council for the Exploration of the Sea has recently been published.* In small compass, it may be said to place before the publics of the different nations represented in the Council the aims and present achievements of marine investigation. Amongst a wealth of valuable and interesting material, the report of the Northern North Sea Committee deserves special mention, as recording a notable landmark in the history of fishery research.

In the work of this Committee, most attention is being given to the herring and the haddock-the two most important commercial fishes of the northern North Sea. As a result of this concentration of effort, there is being built up, slowly but surely, a very definite knowledge of the composition of the stocks of these two species which is of immediate value for an understanding of the fluctuations in the practical fisheries. Much still remains to be accomplished,

* Conseil Permanent International pour l'Exploration de la Mer. Rapports et procès-verbaux des réunions. Vol. 74: Procès-verbaux (Mars 1931). Pp. 203. (Copenhague : Andr. Fred. Høst et fils, 1931.) $7.75 \mathrm{kr}$.

No. 3259, VoL. 129] more particularly with regard to the correlation of these fluctuations in the year classes of fish entering the marketable stocks with the successive changes in hydrographical and biological conditions in the sea.

Nevertheless, the work on the haddock has reached a stage when the yield of the North Sea haddock fisheries for eighteen months or two years ahead can be anticipated with great accuracy. Definite forecasts, made only experimentally as yet, have proved most satisfactory. For example, the general success of a forecast made in April 1929 at the scientific meeting of the International Fisheries Conference in London is cited. At that meeting it was stated that the fairly successful 1926 brood should, for most of its fourth year (1929), serve to provide catches just above normal. By the end of the autumn of that year, however, this brood should have made the greater part of its contribution to the catches. The 1927 brood had proved a failure, so catches would therefore be expected to sink below normal from late autumn 1929 to well on in 1930. But about August of the latter year there should take place a marked increase in the catches owing to the upgrowth of the highly successful 1928 
brood. In 1931 still greater catches should accrue. The course of events in the commercial fishery agreed very closely with the above prediction.

In the report now before us forecasts are made for an ensuing period as far forward as the middle of 1933. After the autumn of 1931, when most of the 1928 brood has been fished out, a sharp drop in the catches is predicted, owing to paucity of the 1929 and 1930 broods. Landings will continue below normal throughout 1932 and during at least the first half of 1933. The result of the 1931 spawning is not known at present, but a good brood is hoped for in order to relieve the depression which always follows when two successive years produce numerically unsatisfactory broods.

G. A. S.

\section{Mobilities of Atmospheric Large Ions}

A RECENT paper by R. K. Boylan entitled "The A Mobilities of Atmospheric Large Ions" * is of obvious importance in the subject of atmospheric electricity, which has engaged the attention of many meteorologists since Elster and Geitel's pioneer researches many years ago. Of the two classes of ion present in atmospheric air, the large ions of small mobility discovered by Langevin are normally the most numerous, and there is general agreement in fixing their mobility at $0.00033 \mathrm{~cm} . / \mathrm{sec} . / \mathrm{volt} / \mathrm{cm}$. These appear to be the principal nuclei of condensation for water vapour, and to be the result of small ions attaching themselves to uncharged particles of dust.

It is pointed out by Boylan that whereas McClelland and P. J. Nolan have found ions of smaller mobility in air treated in various artificial ways, such as bubbling through alcohol or passage over flames, it is generally believed that ions larger than the Langevin ions, that is, ions of smaller mobility, are absent from untreated air. Experiments conducted by Boylan on air in a well-ventilated room in Dublin gave strong reason for disbelieving this conclusion. Experiments were made on the usual lines, air being drawn at measured speeds between two lengths of concentric brass tubing, between which high tension electric fields of various known strengths were maintained, the current being measured by an electrometer. Since ions tend to group themselves around certain mobilities, these groups can be detected by looking for discontinuities in the curve obtained by plotting current against voltage; at such points all the ions of a given mobility are just collected on the inner electrode during the passage of the air through the tube. Boylan used both the McClelland and Zeleny methods of working with this apparatus, and tried many variations of air speed.

Curves derived by both methods agreed in showing clear evidence of the presence of several groups of large ions of mobilities higher and lower than that of the Langevin ions. So far from indicating 'saturation', that is, complete removal of ions, at a voltage corresponding with the mobility of the Langevin ion, the ionisation measured increased by amounts varying from 28 to 200 per cent when sufficient voltage to produce saturation was applied.

The difficulties of accurate measurement of the mobility of each group were very great; for the use of very high voltage or very slow speed, or some compromise between the two, is essential when dealing with such low mobilities, and each gives rise to its particular source of error or uncertainty. For this reason, Boylan does not claim to give a complete or accurate catalogue of the larger ions. Among the principal groups more mobile than the Langevin ions

- Proc. Royal Irish Academy, vol. 40, Section A, No. 4. may be mentioned those of mobility 0.0008 and 0.0006 , and among the less mobile groups those of mobility 0.0009 and 0.00006 . There was striking general agreement with many of the artificially produced groups observed by J. J. Nolan and by McClelland and P. J. Nolan. It is considered that very few of these ions would be found in the air of country districts.

E. V.N.

\section{University and Educational Intelligence}

Applications for Ramsay Memorial fellowships for chemical research, one of which will be limited to candidates educated in Glasgow, will be considered by the trustees at the end of June. Particulars of the fellowships can be obtained from the Secretary, Ramsay Memorial Fellowship Trust, University College, Gower Street, W.C.1. The application forms must be received by, at latest, May 31 .

THE Carnegie Trust for the Universities of Scotland has recently had under consideration the question whether, in view of the public assistance now available to the Scottish university student, the payment of class fees from funds dedicated under the Trust deed to this object should be continued. In its thirtieth annual report, the Trust's executive committee declares that the system whereby education authorities assist necessitous and deserving students has not yet reached in practice such a stage of development and uniformity as would warrant the immediate withdrawal from those eligible of the payment in part of class fees by the Trust, and that the special circumstances of the times are such as to render any such new departure inexpedient for the present. The amount spent by the Trust in this way in 1930-31 was $£ 56,366$. During the past four years, inquiry into the financial circumstances of each applicant's household has been made before admission to the benefits of the Trust, and it has been determined that in the case of all entrants to the university under twenty-one years of age the minimum standard of requirement for admission to these benefits shall be the obtaining of higher grade passes in three subjects in the Leaving Certificate Examination or in recog. nised equivalents. During the year, former beneficiaries have repaid a sum of $£ 1891$ voluntarily. The 'Trustees' scheme for the endowment of research is reported to be functioning very successfully. The awards, however, are limited to $£ 16,000$ a year, which is only half of the aggregate of the grants applied for.

"RADIo and Education" is the title of a short historical survey issued by the Office of Education, Washington, of the educational uses of wireless transmission in America. The work of amateurs is one phase of education by radio which the United States Army and Navy have in the past done much to foster. At the present time, there is a vast amount of direct instruction by broadcast lectures, one of the most important examples of which is the National Broadcasting Company's music appreciation hour directed by Walter Damrosch in connexion with the concerts of the New York Symphony Orchestra and listened to by some millions of pupils at every lecture. The 'American School of the Air' gives a half-hour period of instruction daily in historical drama, Nature study, vocational guidance, and a wide range of other topics which fit into the curricula of the public schools. Of the enterprises of State departments in this field, the Ohio School of the Air is the most extensive and thorough. Its programmes, comprising geography, rhythmic exercise, French, and other high-school subjects, are broadcast one hour each day and are

No. 3259, VoL. 129] 